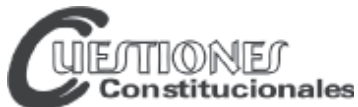

Revista Mexicana de Derecho Constitucional

Núm. 25, julio-diciembre 2011

\section{LOS JUECES DE CONTROL EN EL SISTEMA ACUSATORIO. ¿UN NUEVO ÓRGANO DE CONTROL CONSTITUCIONAL EN MÉXICO?}

\author{
CONTROLLING JUDGES IN THE ACCUSATORY SYSTEM. \\ A NEW ORGAN OF CONSTITUTIONAL CONTROL IN MEXICO
}

\section{Salvador CASTILLO GARRIDO*}

RESUMEN: El autor propone la tesis de que, en términos de una interpretación lógica y sistemática del artículo 16 constitucional, párrafo décimo cuarto, los jueces de control en el sistema acusatorio en México, en su función de garantía, deben ser considerados como un nuevo mecanismo de control constitucional porque al custodiar derechos fundamentales de los indiciados, las víctimas u ofendidos, tales como la inviolabilidad de su domicilio, la dignidad humana y la reparación del daño, protegen no sólo esos derechos subjetivos sino la propia Constitución.

Palabras clave: derechos fundamentales, defensa de la Constitución, control difuso, jurisdicción constitucional de la libertad.
ABSTRACT: The author proposes the thesis that, in accordance with a logical and systematic interpretation of article 16 , paragraph 14 of the mexican Constitution, the controlling judiciaries within the country's accusatory system, in accordance with their guaranteeing role, should be considered as a new mechanism of constitutional control because, upon protecting the fundamental rights of the accused, the victim, or other persons affected by the crime (such as the inviolability of their home, human dignity, and reparation of harm), they protect not only these subjective rights but also the Constitution itself.

Descriptors: fundamental rights, defense of the Constitution, fuzzy control, constitutional jurisdiction of liberty.

Magistrado de Circuito, adscrito al Segundo Tribunal Colegiado de Circuito del Centro Auxiliar de la Cuarta Región, con residencia en Xalapa, Veracruz; doctorando en derecho por la Universidad Cristóbal Colón de Veracruz, en coordinación con el Instituto de Investigaciones Jurídicas de la UNAM. 


\section{INTRODUCCIÓN}

El 18 de junio de 2008 se publicó en el Diario Oficial de la Federación el decreto de reformas a la Constitución Política de los Estados Unidos Mexicanos, que establece las bases para un nuevo sistema procesal penal acusatorio que tendrá que ser implementado en un plazo no mayor de ocho años.

El Constituyente Permanente autorizó la incorporación de jueces de control, en el artículo 16 constitucional, párrafo décimo tercero (hoy décimo cuarto), en estos términos:

Los poderes judiciales contarán con jueces de control, que resolverán, en forma inmediata, y por cualquier medio, las solicitudes de medidas cautelares, providencias precautorias y técnicas de investigación de la autoridad, que requieran control judicial, garantizando los derechos de los indiciados y de las víctimas u ofendidos.

En la exposición de motivos se aclara que no se refiere al antiguo juez de instrucción, en sustitución de la autoridad persecutora del delito, por lo que la figura de jueces de control es una propuesta de impacto transversal, por estar vinculada a varias modificaciones del artículo 16 de la ley fundamental, pues establece jueces federales y locales denominados de control que se avoquen fundamentalmente a resolver los pedimentos ministeriales de medidas cautelares, providencias precautorias, técnicas de investigación para resolverlos de forma inmediata, para minimizar los riesgos de la demora en la ejecución de la diligencia, ello con el fin de que tales medidas se resuelvan en forma acelerada y ágil, sin que ello implique dejar de fundar y motivar concretamente sus resoluciones que podrán ser comunicadas por cualquier medio fehaciente y contenga los datos requeridos.

El poder reformador estableció que el juez de control también tendrá atribuciones para conocer de las resoluciones de reserva, no ejercicio de la acción penal, el desistimiento y la suspensión de la acción penal para controlar su legalidad y, en todos los casos señalados, resguardar los derechos de los imputados, las víctimas y ofendidos.

También se determinó que al no visualizarse a corto plazo la posibilidad de que en cada ciudad haya jueces especializados en materia penal, como para asignar al menos uno la función de control, otro a la función preparatoria, uno más para los juicios y un último para la ejecución de las sanciones 
penales; entonces, los legisladores establecieron un marco constitucional flexible para permitir diversas formas de organización sobre las bases del sistema acusatorio oral, tanto para el fuero federal como para el fuero común y que por ello, este tipo de jueces podrán ser los que substancien las audiencias del proceso, preliminares al juicio, ya que dependerá de la organización que las leyes establezcan pero también de las cargas laborales y los recursos disponibles en cada lugar.

La disposición jurídica que incorpora a los jueces de control al sistema de administración de justicia penal, en sus ámbitos federal y local, no tiene la claridad que en el caso se requería para identificar su naturaleza y el alcance preciso de sus atributos.

Existen por lo menos cuatro deficiencias:

a) no contempla todas y cada una de las atribuciones que, según la minuta de los congresistas, corresponderán a los jueces de control;

b) no identifica ninguna clase de instrumento o mecanismo para que los jueces de control garanticen los derechos fundamentales;

c) no quedó perfilado el sistema de recursos que operará en caso de inconformidad con sus resoluciones;

d) la alusión que se hace en el artículo 16 constitucional, en torno a que los jueces de control al emitir sus resoluciones sobre medidas cautelares o técnicas de investigación, lo hagan "garantizando los derechos de los indiciados y de las víctimas u ofendidos"; proporciona muy poca información para delinear claramente el alcance de la jurisdicción que se asigna como garantes de esos derechos.

En la propia minuta, los legisladores manifestaron que en el ámbito constitucional sólo deben establecerse las atribuciones fundamentales y remitir el desarrollo de las garantías a la legislación secundaria, para no sobre regular en nuestra Constitución; pero creo que no indicaron las bases fundamentales que permitan establecer el alcance de las competencias que tendrían los jueces de control en este rubro.

Esta ambigüedad se patentiza, si se tiene en cuenta que también se determinó que los jueces de control sustituyan a los jueces de amparo, en el conocimiento de las reclamaciones provenientes del ofendido y/o las víctimas contra las decisiones del Ministerio Público sobre no ejercicio y 
desistimiento de la acción penal, pero no se explica, ni se descarta, si al realizar estas atribuciones asumirán también un rol de regularidad de la Constitución similar al desplegado por los jueces de distrito en el amparo.

Esta problemática fue advertida por los especialistas del Centro de Estudios de Justicia de las Américas (CEJA), quienes en su proyecto de investigación sobre la implementación de la reforma procesal destacaron que:

En el diseño que define la reforma constitucional, se ha hecho referencias a las funciones propias del Juez de control y del Juez de juicio, como también a las posibles funciones de un Juez de ejecución y la necesidad de discusión del establecimiento de esa figura. Pero este caso involucra algunas otras consideraciones que se han mencionado y que no se encuentran reguladas en forma específica por la reforma constitucional: ¿cuál Juez será encargado de resolver las impugnaciones en contra de las decisiones del Juez de control y/o del Juez de juicio?

Adicionalmente, en función a que las atribuciones del Juez de control serán básicamente, las que hoy desempeña el juzgado encargado de decidir los amparos indirectos, es importante determinar la necesidad de reforma en la tramitación de este recurso (ya sea a partir de la conversión de los Jueces que tienen a su cargo el mismo en Jueces de control y la limitación del recurso a ámbitos no penales, ya sea diferenciando casos en los que se podrá aun disponer del amparo indirecto en procesos penales). ${ }^{1}$

El doctor Sergio García Ramírez, quien también se ha ocupado de dar seguimiento a la reforma constitucional penal, coincide en que la normatividad relativa a los jueces de control carece de la claridad que era indispensable en el caso, por tratarse de una figura novedosa. En este sentido, García Ramírez ha expresado que:

...la regulación constitucional no resulta particularmente clara, quizás porque la Ley Suprema no ofrece una articulación del procedimiento que permita establecer el curso de éste, distinguir sus etapas y precisar la intervención que en cada una de ellas tendrán las autoridades jurisdiccionales llamadas a participar. Desde luego, reconozco que la Constitución no tendría por qué fijar con detalle la estructura del enjuiciamiento. Ya hay bastantes normas

1 Suprema Corte de Justicia de la Nación, El sistema penal acusatorio en México: Estudio sobre su implementación en el Poder Judicial de la Federación, México, 2008, pp. 118 y 119. 
reglamentarias como para que sea necesario agregar precisiones de este carácter... empero, el establecimiento de esas atribuciones fundamentales debe ser explícito y claro, sobre todo cuando se trata de incorporar novedades relevantes en un procedimiento que durante más de un siglo ha tenido características diferentes de las que pretende imprimir la RC, y más aún si se considera que a partir de las normas constitucionales comenzará la enorme etapa de construir el nuevo sistema de justicia penal, entidad por entidad, a través de decisiones legislativas autónomas que deben instalarse en cimientos uniformes, perfectamente definidos...".2

Con base en estos antecedentes, este trabajo aborda una cuestión central: ¿es posible considerar la jurisdicción de los jueces de control como un nuevo mecanismo de regularidad constitucional?

Y, una cuestión subsidiaria: ¿en qué forma debe articularse el control de los jueces de control en su función de garantía y el juicio de amparo?

En este trabajo intentaré justificar que los jueces de control o garantía, conforme a la interpretación lógica y sistemática del artículo 16 constitucional, pueden ser considerados como depositarios de un nuevo mecanismo de regularidad constitucional, porque al custodiar derechos fundamentales como la inviolabilidad del domicilio, el secreto de las comunicaciones privadas, la libertad personal y de tránsito, la dignidad humana, la eventual reparación del daño, la protección de las víctimas, entre otros, van a proteger o garantizar no solamente esos derechos subjetivos públicos, si no la propia carta fundamental, sin que ello implique el despliegue del llamado control difuso que, hasta ahora está proscrito por la jurisprudencia del máximo tribunal del país.

El nivel de estudio es propositivo e interpretativo, en la medida que examina la naturaleza y atribuciones de los jueces de control, para llegar a proponer la tesis, que deben ser considerados como un nuevo instrumento de control o defensa de la Constitución y que su función de garantía, complementa o sustituye, en algunos casos al juicio de amparo indirecto en materia penal.

Este artículo se organiza en cuatro partes, en la primera se repasan muy brevemente algunas nociones sobre el concepto de defensa de la Constitución y se enuncian los instrumentos y mecanismos de regularidad constitucional en México; en la segunda se aborda la interpretación de la Suprema Corte

2 García Ramírez, Sergio, La reforma constitucional en materia penal (Jornadas de Justicia Penal), México, Instituto Nacional de Ciencias Penales, 2009, p. 60. 
sobre el control judicial de la Constitución en nuestro país; en la tercera se proponen dos vertientes contrapuestas sobre la naturaleza de los jueces de control y al final, se propone un esquema para articular la función de garantía de los jueces de control y el juicio de amparo indirecto penal.

\section{CONCEPTO DE DEFENSA DE LA CONSTITUCIÓN}

A casi cien años de la promulgación de la Constitución de 1917, el control constitucional en nuestro sistema jurídico ha experimentado modificaciones sustanciales que tienen que ver con el incremento de los mecanismos de regularidad constitucional.

Inicialmente, el texto constitucional contempló solamente cuatro instrumentos de control, a saber: a) el procedimiento de investigación de la Suprema Corte de Justicia de la Nación (previsto actualmente en el artículo 97, párrafo segundo constitucional); b) el juicio político o de responsabilidad de los altos funcionarios (previsto ahora en el artículo 110 constitucional); c) el juicio de amparo (establecido en los artículos 103 y 107 constitucionales); d) las controversias constitucionales (instrumentado en el artículo 105, fracción I constitucional).

Los cuatro instrumentos anteriores han sido objeto de diversas modificaciones o reformas, de las cuales no me ocuparé en este trabajo, porque mi interés reside en mostrar que la justicia constitucional es dinámica, lo que permite el mejoramiento o incremento de los remedios para lograr la efectividad de la norma fundamental.

Es así, que en la década de los años noventa del siglo XX se introdujeron nuevos mecanismos de regularidad constitucional: a) el juicio de revisión constitucional electoral (artículo 99, fracción IV constitucional); b) el juicio de protección de los derechos político electorales (artículo 99, fracción V constitucional); c) la facultad del Tribunal Electoral del Poder Judicial de la Federación para resolver la no aplicación de leyes (en esa materia) contrarias al texto constitucional (artículo 99, fracción IX, párrafo segundo constitucional); d) los organismos autónomos protectores de los derechos humanos (artículo 102, apartado B constitucional); e) la acción abstracta de inconstitucionalidad (artículo 105, fracción II constitucional).

En palabras del ministro de la Suprema Corte de Justicia de la Nación, Arturo Zaldívar Lelo de Larrea, la defensa de la Constitución ha tenido que responder a nuevos retos y se ha visto obligada a ampliar su objeto 
y sus efectos, ante las cambiantes circunstancias políticas y sociales del siglo XX.

Para este jurista la defensa de la Constitución se ocupa de la normalidad constitucional; este sector se integra por todos aquellos instrumentos que coadyuvan a que el sistema previsto en la Constitución funcione. Por otra parte, la defensa constitucional regula los instrumentos predominantemente de carácter procesal que permiten lograr la operatividad de las normas fundamentales cuando existe una violación de cualquier tipo respecto de dichas normas. La defensa constitucional comprende la protección constitucional (normalidad constitucional) y las garantías constitucionales (anormalidad constitucional).

Estas garantías constitucionales, para Lelo de Larrea, son instrumentos jurídicos predominantemente de carácter procesal, que tienen por objeto lograr la efectividad de las normas fundamentales cuando existe incertidumbre, conflicto o violación de las mismas. La defensa de la Constitución en sentido estricto se identifica con las garantías constitucionales. A este sector, dice el doctor Lelo de Larrea, la doctrina, se ha referido, indistintamente, como justicia constitucional, jurisdicción constitucional y control de la constitucionalidad, que se caracteriza por su carácter evolutivo. ${ }^{3}$

En opinión del doctor Héctor Fix-Zamudio ${ }^{4}$ la defensa de la Constitución está integrada por todos aquellos instrumentos jurídicos y procesales que se han establecido tanto para conservar la normativa constitucional como para prevenir su violación, reprimir su desconocimiento y, lo que es más importante, lograr el desarrollo y la evolución de las propias disposiciones constitucionales en un doble sentido: desde el punto de vista de la Constitución formal lograr su paulatina adaptación a los cambios de la realidad político-social, y desde el ángulo de la Constitución material su transformación de acuerdo con las normas programáticas de la propia carta fundamental. Para este jurista, la defensa de la Constitución puede escindirse en dos categorías fundamentales: la protección de la Constitución y las llamadas garantías constitucionales.

3 Zaldívar Lelo de Larrea, Arturo, "El juicio de amparo y la defensa de la Constitución”, Cossío, José y Pérez de Acha, Luis M. (comps.), La defensa de la Constitución, México, Fontamara, 1997, pp. 48-50.

4 Los conceptos aquí mencionados, aparecen en diversas publicaciones del propio autor, y para efectos de consulta he recurrido al libro intitulado Justicia constitucional ombudsman y derechos humanos, Comisión Nacional de Derechos Humanos, 1997, pp. 257-302. 
El primer sector, relativo a la protección de la Constitución, está integrado por todos aquellos instrumentos, políticos, económicos, sociales y de técnica jurídica que han sido canalizados por medio de normas de carácter fundamental e incorporados a los documentos constitucionales, con el propósito de limitar el poder y lograr que sus titulares se sometan a los lineamientos establecidos en la propia Constitución. En este campo, aparecen la división de poderes, la regulación de los recursos económicos y financieros, la institucionalización de los factores sociales: grupos de interés, grupos de poder y partidos políticos, la supremacía constitucional y el procedimiento dificultado de reforma.

Las garantías constitucionales, según este autor, pueden describirse como los instrumentos jurídicos, predominantemente de carácter procesal, que tienen por objeto lograr la efectividad de las normas fundamentales cuando existe incertidumbre, conflicto o violación de las referidas normas.

En esta categoría se encuentran la jurisdicción constitucional de la libertad, la jurisdicción constitucional orgánica y la jurisdicción constitucional de carácter internacional y comunitario.

De estas últimas tres categorías, la que tiene interés para este trabajo es la denominada jurisdicción constitucional de la libertad, que puede definirse, siguiendo al profesor Fix-Zamudio, como aquel conjunto de instrumentos jurídicos y predominantemente procesales dirigidos a la tutela de las normas constitucionales que consagran los derechos fundamentales de la persona humana en sus dimensiones individual y social.

Estos instrumentos protectores se subdividen, a su vez, en tres categorías: los indirectos, o sea aquéllos que están dirigidos a la tutela de los derechos ordinarios, pero que a falta o en apoyo a los específicos, también funcionan para realizar los derechos fundamentales, tales como el proceso ordinario y la justicia administrativa. Un segundo sector se refiere a la represión de las violaciones consumadas de los Derechos Humanos por parte de los órganos del poder, y los podemos calificar de medios complementarios, entre los cuales se pueden señalar, el juicio político de los altos funcionarios y la responsabilidad patrimonial del Estado. Finalmente, los medios específicos son aquellos establecidos para la tutela directa de los derechos fundamentales de los gobernados, pues implican la existencia de procedimientos sencillos y breves para la reparación de las infracciones a los propios derechos, restituyendo a los afectados en el goce de los mismos. 
En este sector, Fix-Zamudio, identifica un conjunto de instrumentos que cumplen la función de la tutela directa de los derechos humanos como el habeas corpus; el juicio de amparo regulado por los ordenamientos de varios países latinoamericanos y por la legislación española, incluyendo al mandado de segurança; el control judicial de la constitucionalidad de las leyes, cuando afectan los derechos subjetivos de los reclamantes, y algunos medios de impugnación específicos del derecho europeo continental (recurso constitucional). Fix-Zamudio agrega en esta clasificación al ombudsman de origen escandinavo, aunque este último no puede considerarse como instrumento procesal, en sentido estricto.

La expresión de jurisdicción constitucional de la libertad fue acuñada por Mauro Cappelletti, en su obra clásica del mismo nombre, publicada originalmente en Milán en 1955. ${ }^{5}$ En esta obra, el maestro italiano analizó el "recurso constitucional" (Verfassungsbeschwerde) implementado, en esa época, en la República Federal Alemana. Consistía en un medio de reclamo jurisdiccional ante el Tribunal Constitucional federal, que podía ejercitarse por los ciudadanos particulares para la tutela de sus derechos fundamentales y de algunas otras situaciones subjetivas lesionadas por un acto de cualquiera autoridad pública. El legitimado para obrar era todo aquél que se afirmase titular del derecho fundamental que haya sido lesionado por actos de la autoridad jurídica. La infracción de la que nace el interés para obrar consistiría, no en un simple peligro de daño futuro, sino en un perjuicio actual, resultante de la negativa de una facultad o de la determinación de un deber en forma contraria a lo dispuesto por los preceptos sobre los derechos fundamentales o de otros derechos que hayan sido equiparados a los primeros. Por virtud del recurso, decía Cappelletti, se abría al individuo la posibilidad de convertirse en la manera más directa en factor activo de la vida del derecho y del Estado, por medio del mismo acto en el cual defiende sus intereses supremos, es decir, su libertad.

El profesor español José Luis Cascajo Castro, se ha ocupado también de la denominada jurisdicción constitucional de la libertad.

Este autor explica que si bien el principal objeto de la justicia constitucional viene representado por el control de constitucionalidad de las leyes no se puede reducir su ámbito a dicha función, so pena de ignorar otras

5 Cappelletti, Mauro, La giurisdizione costituzionale delle libertà, Milán, Giuffrè, 1955. Hay traducción al castellano de Héctor Fix-Zamudio, La jurisdicción constitucional de la libertad, UNAM, México, 1961. 
estimables manifestaciones tales como: tutela de los derechos fundamentales frente a cualquier disposición de los poderes públicos, resolución de los conflictos de atribuciones entre los poderes del Estado, enjuiciamiento de las actividades ilícitas de los titulares de órganos constitucionales (la llamada justicia política), control sobre la legitimidad constitucional de los partidos políticos, además de posibles funciones contencioso-electorales o meramente declarativas.

Cascajo Castro, a título de presupuestos conceptuales, aclara que hay que distinguir diversas ópticas desde las que se puede contemplar la jurisdicción constitucional. Por una parte, como jurisdicción que tutela la regularidad constitucional del ejercicio o actividad de determinados órganos constitucionales con un carácter fundamentalmente objetivo. Y, por otra, como jurisdicción que pretende actuar y hacer valer las situaciones jurídicas subjetivas del ciudadano, previamente constitucionalizadas, que redundan también en una tutela y garantía de la norma constitucional, pero que presenta fundamentalmente un carácter subjetivo en cuanto pretende satisfacer dichas situaciones jurídicas subjetivas que la Constitución imputa y atribuye a los individuos. ${ }^{6}$

Joaquín Brage Camazano, en su libro La jurisdicción constitucional de la libertad (Teoría General, Argentina, México, Corte Interamericana de Derechos Humanos) $)^{7}$ realiza un análisis profundo de la jurisdicción constitucional de la libertad y enfatiza que es conveniente arbitrar procedimientos específicos para prevenir o, en su caso, reparar la violación de los derechos fundamentales, debiendo caracterizarse por la rapidez, la brevedad y la efectividad y ello al margen de si en ese país hay un tribunal constitucional.

Este autor asegura, con mucha razón, que los derechos valen lo que valen sus garantías. Se comprende, así dice, la necesidad de habilitar tales garantías para que el ejercicio de los derechos y libertades fundamentales se torne real y efectivo, para que cualquier ciudadano pueda resistir por medios jurídico-procesales frente a terceros particulares (directa o indirectamente), frente a la Administración, frente a los mismos jueces e incluso frente al mismo soberano legislador cuando se ejecute o trate de ejecutar una activi-

6 Cascajo Castro, José Luis, La jurisdicción constitucional de la libertad, 1975, consultado en http://www.cepc.es/rap/Publicaciones/Revistas/2/REP_199_153.pdf.

7 Cfr. Brage Camazano, Joaquín, La jurisdicción constitucional de la libertad, México, Porrúa, 2005, pp. 17, 18, 28, 41, 42, 53, 54, 55. 
dad, o se deje de hacerlo cuando se debía ejecutar, con vulneración de los propios derechos fundamentales, tutelados por la Constitución, obteniendo asimismo, en su caso, la restitución al status quo ante previo a la violación del derecho o la correspondiente reparación por la lesión producida.

En opinión de este investigador español, es viable atribuir a los jueces ordinarios, o a algunos de ellos, la competencia para conocer de estos instrumentos procesales específicos de tutela de los derechos fundamentales. Si así sucede, el autor sugiere que se otorgue además, una competencia unificadora y orientadora básica al tribunal constitucional y/o al tribunal supremo correspondientes, a fin de evitar una aplicación inaceptablemente desigual dentro del Estado, y ello incluso en los Estados federales o descentralizados, porque estos derechos han de considerarse precisamente como expresión formal de convicciones ético-jurídicas comunes.

Conforme a este modelo, la jurisdicción constitucional de la libertad no queda integrada solo por el tribunal constitucional en los países donde exista, sino también por todos y cada uno de los tribunales que, en su caso, tengan competencia para conocer de los procesos constitucionales específicos para la tutela de los derechos fundamentales.

Estas ideas encuentran conexión con el pensamiento del magistrado del Tribunal Electoral del Poder Judicial de la Federación, Manuel González Oropeza, quien en una obra reciente ${ }^{8}$ ha incluido un capítulo dedicado al desarrollo de la garantía jurisdiccional de la Constitución y de los derechos humanos, en la que a título de consideraciones generales ha señalado que la consagración y protección de los derechos humanos no corresponde en exclusividad a ningún ámbito de gobierno, sino que es una responsabilidad que la Constitución federal y las demás normas del sistema jurídico imponen a todas las autoridades, sean federales, locales o municipales, así como ejecutivas, legislativas, judiciales u organismos autónomos, y que la naturaleza de los derechos del hombre no se rige por el principio de distribución de competencias del Estado federal, de acuerdo con el artículo 124 constitucional, el cual sólo se aplica a las atribuciones o competencias de la Federación y los estados, pero la naturaleza de los derechos humanos es

8 González Oropeza, Manuel, Constitución y derechos humanos, orígenes del control jurisdiccional, México, Porrúa, 2009, pp. 339-341. 
distinta a la de las atribuciones, pues no son potestades, sino limitaciones a todas las potestades. ${ }^{9}$

\section{LA INTERPRETACIÓN DE LA SUPREMA CORTE SOBRE EL CONTROL JUDICIAL DE LA CONSTITUCIÓN}

El máximo tribunal del país ha establecido jurisprudencia en el sentido de que el artículo 133 constitucional no es fuente de facultades de control constitucional para los jueces del orden común. La jurisprudencia de la Suprema Corte de Justicia de la Nación surgió para definir el debate doctrinal y judicial que desde hace muchos años ha existido en nuestro país, en torno al alcance que debe darse a la segunda parte de ese precepto que establece: "Los jueces de cada Estado se arreglarán a dicha Constitución, leyes y tratados, a pesar de las disposiciones en contrario que pueda haber en las Constituciones o leyes de los Estados".

Los ministros del alto tribunal del país, al pronunciarse sobre ese tema señalaron que es inadmisible sostener que, con fundamento en lo dispuesto por el artículo 133 de la Constitución general de la República, los jueces del orden común puedan abstenerse de aplicar las leyes locales, en base al argumento de que éstas son violatorias de la Ley Suprema; porque aun cuando en principio la redacción del artículo 133 constitucional sugiere esa posibilidad, lo cierto es que la postura sustentada hasta la fecha por la Corte ha sido en el sentido opuesto teniendo en cuenta una interpretación sistemática del mismo precepto y los principios que conforman la Constitución. ${ }^{10}$

9 Para la Suprema Corte de Justicia de la Nación, la tutela de las llamadas garantías constitucionales puede ser analizada bajo la óptica de invasión de esferas competenciales entre Estado y la Federación. Así se desprende del contenido de la ejecutoria y votos particulares, de la cual surgió la tesis de rubro: "CONTROVERSIA CONSTITUCIONAL. LA FACULTAD OTORGADA A LA SALA CONSTITUCIONAL DEL TRIBUNAL SUPERIOR DE JUSTICIA DEL ESTADO DE VERACRUZ-LlaVE PARA CONOCER Y RESOLVER EL JUICIO DE PROTECCIÓN DE DERECHOS HUMANOS, PREVISTO EN LA CONSTITUCIÓN POLÍTICA DE ESA ENTIDAD FEDERATIVA, NO INVADE LA ESFERA DE ATRIBUCIONES DE LOS TRIBUNALES DE LA FEDERACIÓN, PUES AQUÉL SE LIMITA A SALVAGUARDAR, EXCLUSIVAMENTE, LOS DERECHOS HUMANOS QUE ESTABLECE EL PROPIO ORDENAMIENTO LOCAL". Semanario Judicial de la Federación y su Gaceta, Novena Época, Pleno, T. XV, junio de 2002, p. 406.

10 Estas ideas se encuentran recogidas en la tesis de jurisprudencia que a continuación se transcribe: Tesis: P./J. 73/99, Semanario Judicial de la Federación y su Gaceta, Novena Época, t. X, agosto de 1999, p. 18, de rubro siguiente: "CONTROL JUDICIAL DE LA CONSTITUCIÓN. ES ATRIBUCIÓN EXCLUSIVA DEL PODER JUDICIAL DE LA FEDERACIÓN”. 


\section{LOS JUECES DE CONTROL ¿ÓRGANOS DE REGULARIDAD CONSTITUCIONAL?}

Como hemos visto, la defensa constitucional, en una de sus vertientes, está representada por instrumentos generalmente procesales (garantías), que tienen por objeto lograr la eficacia de sus normas, ante su posible desconocimiento o violación.

En el plano de la llamada jurisdicción de la libertad, existen medios jurídicos y procesales que han ido surgiendo para la rápida y eficaz protección a derechos fundamentales de manera directa y generalmente con efectos reparadores.

La doctrina ha considerado que al tutelarse derechos subjetivos públicos se tutela a la vez la norma constitucional y que, la consagración y protección de los derechos fundamentales no corresponde en exclusividad a ningún ámbito de gobierno, sino que es una responsabilidad que corresponde a todas las autoridades y que, incluso, es viable atribuir a jueces ordinarios la competencia para conocer de instrumentos procesales rápidos y sencillos para prevenir o no, en su caso, reparar la violación de los derechos fundamentales.

¿Es éste el caso del nuevo control jurisdiccional asignado a los jueces de control? ¿Es posible considerar a la jurisdicción de los jueces de control, en su función de garantía, como un nuevo instrumento procesal para la defensa de la Constitución?

Primera vertiente: los jueces de control no deben ser considerados como un nuevo mecanismo de regularidad constitucional.

Esta posición puede encontrar soporte en los siguientes argumentos:

a) El Constituyente Permanente se constriñó a mencionar en el artículo 16 constitucional, párrafo décimo tercero (hoy décimo cuarto), que los jueces de control resolverán, en forma inmediata, y por cualquier medio, las solicitudes de medidas cautelares, providencias precautorias y técnicas de investigación de la autoridad, que requieran control judicial, garantizando los derechos de los indiciados y de las víctimas y ofendidos. Mas no dijo expresamente, que los jueces de control de los poderes judiciales, federal y locales iban a erigirse en un nuevo mecanismo de defensa de la Constitución, por lo que no es válido forzar la interpretación del artículo 16 constitucional, en el sentido de que la garantía que ofrecerán al resolver sobre medidas cautelares, providencias precautorias y técnicas de investigación sea equivalente a la de un juez constitucional, quien si tiene facultades concretas para declarar la violación de un 
derecho fundamental y, para ordenar en su caso, la restitución del orden constitucional.

b) Si se revisa la minuta de los congresistas, puede llegarse a la conclusión que no fue su intención dar vida, a un nuevo instrumento de regularidad constitucional, sino únicamente establecer un control formal de legalidad sobre el proceder del Ministerio Público; incapaz de remplazar al juicio de amparo que, bajo esa tónica, debe seguir utilizándose en caso de infracción a derechos fundamentales por parte de las autoridades investigadoras de los delitos e, incluso, en contra de los propios autos y resoluciones de los jueces de control cuando sea imputable a ellos la vulneración del derecho fundamental.

c) Esto último puede encontrar respaldo en la iniciativa de reforma a la Ley de Amparo, elaborada por el senador Jesús Murillo Karam, a nombre propio y de Senadores de diversos grupos parlamentarios turnada recientemente a las Comisiones Unidas de Justicia; de Gobernación, y de Estudios Legislativos de la Cámara de Senadores. En ese proyecto de decreto de reformas a la Ley Reglamentaria de los Artículos 103 y 107 de la Constitución Política de los Estados Unidos Mexicanos, en el artículo 107, relativo a los casos de procedencia del amparo indirecto se indica textual, lo que sigue: "Artículo 107. El amparo indirecto procede: (...) VII. Contra las omisiones del ministerio público en la investigación de los delitos, así como las resoluciones de reserva, no ejercicio, desistimiento de la acción penal, o por suspensión de procedimiento cuando no esté satisfecha la reparación del daño".

Segunda vertiente: los jueces de control al ejercer la tutela de los derechos fundamentales de los imputados, las víctimas y los ofendidos deben ser considerados como órganos de regularidad constitucional.

a) Es cierto que el Constituyente Permanente, en el artículo 16, párrafo décimo tercero (ahora décimo cuarto) constitucional, no dijo expresamente que los jueces de control ejercerían una especie de regularidad constitucional; sin embargo, precisó que deberán ser garantes de derechos fundamentales de los inculpados, el ofendido y la víctima.

Con base en lo anterior, estimo que si sus determinaciones en medidas cautelares, providencias precautorias y técnicas de investigación, se proyectan o tienen injerencia en los derechos fundamentales de los imputados, las víctimas u ofendidos, es viable estimar que tal garantía, es constitutiva en sí misma de un instrumento procesal de defensa indirecta de la Constitución.

b) Son jueces creados ex profeso por el Constituyente Permanente para garantizar los derechos de los imputados, el ofendido y la víctima y esas 
prerrogativas de los intervinientes en el proceso criminal, se encuentran consignadas en los apartados $\mathrm{B}$ y $\mathrm{C}$ del artículo 20 constitucional reformado, que consignan a nivel de la carta fundamental los derechos de toda persona imputada y los de la víctima o del ofendido.

Por tanto, la tutela jurisdiccional de los jueces de control no abarca solamente derechos procesales, sino derechos fundamentales, tales como la libertad, la intimidad, la inviolabilidad del domicilio, y la dignidad humana.

c) La jurisdicción que directamente otorga la Constitución a los jueces de control — conforme a las ideas del profesor José Luis Cascajo Castropretende actuar y hacer valer las situaciones jurídicas subjetivas del ciudadano, previamente constitucionalizadas, que redundan también en tutela y garantía de la norma constitucional, pero que presenta fundamentalmente un carácter subjetivo, en cuanto pretende satisfacer dichas situaciones jurídicas subjetivas que la constitución imputa y atribuye a los individuos.

d) Si la jurisdicción constitucional de la libertad —en definición de Héctor Fix-Zamudio - es el conjunto de instrumentos jurídicos y predominantemente procesales dirigidos a la tutela de las normas constitucionales que consagran derechos fundamentales, es viable, incluir en ese esquema a los jueces de control; porque se les faculta para que lleven a cabo la protección de derechos fundamentales consignados en la parte dogmática de la Constitución, con similares características que los del juicio de garantías. Los jueces de control deberán prestar una protección rápida y eficaz, a los reclamos de los involucrados en los procesos penales relacionados con injerencias a sus derechos fundamentales.

e) Es de puntualizarse, que la Suprema Corte de Justicia de la Nación ha venido rechazando que el artículo 133 sea fuente de un control constitucional difuso. Para los ministros de la Corte, la interpretación de esa norma no permite estimar que los jueces del orden común o incluso los federales cuando realizan funciones materialmente jurisdiccionales, puedan intervenir en el cuidado de la regularidad constitucional, pero naturalmente no ha proscrito, ni podría hacerlo, que el Constituyente Permanente, en uso de sus atribuciones incorpore procesos nuevos para la defensa de la Constitución, específicamente de los derechos fundamentales.

f) En la exposición de motivos de la reforma constitucional, se estableció que los jueces de control tendrán competencias para conocer de las impugnaciones del ofendido y la víctima en contra de las resoluciones del Ministerio Público sobre no ejercicio y desistimiento de la acción penal; por 
lo que puede estimarse que al desplegar materialmente la misma función que hoy realizan los jueces de amparo, el papel que debe asignárseles, no es otro, sino el de órganos de control constitucional, lo que puede evitar la duplicidad de funciones que se va a propiciar si se mantiene la posibilidad de impugnar en amparo indirecto esa clase de asuntos, como se contempla en el proyecto de reformas a la Ley de Amparo.

g) El amparo ha desarrollado un significativo papel en la defensa de los derechos fundamentales, pero es necesario dar paso a nuevas formas de protección de esos derechos, sobre todo si se traducen en instrumentos específicos de formulación sencilla y expedita para la tutela efectiva de los derechos fundamentales.

h) Los jueces de control de las entidades federativas y los jueces de distrito que sean adscritos con ese carácter están ampliamente capacitados para desarrollar la función de verdaderos garantes de derechos fundamentales. ${ }^{11}$ Se nos hace difícil pensar que sea necesario que la resolución de un juez de distrito (que actuó como juez de control) relativa a una decisión del Ministerio Público sobre no ejercicio de la acción penal amerite a su vez, ser pasada bajo el tamiz del juicio de amparo, que sería resuelto por otro juez de distrito con idénticas habilidades.

i) En la investigación realizada por el Centro de Estudios de Justicia de las Américas se destacó que en función de que las atribuciones del juez de control serán básicamente las que hoy desempeña el juzgado encargado de decidir los amparos indirectos, es importante, determinar la necesidad de reforma en la tramitación de este recurso, ya sea a partir de la conversión de los jueces que tienen a su cargo el mismo, en jueces de control y la limitación del recurso a ámbitos no penales. Para los investigadores

11 Es así, porque incentivados por el Poder Judicial de la Federación (que cuenta con el Instituto de la Judicatura Federal) y por organismos internacionales (como la Agencia Española de Cooperación Internacional que colabora con la Comisión Nacional de Tribunales Superiores de Justicia de los Estados Unidos Mexicanos A. C.), actualmente la mayoría de los poderes judiciales locales cuentan con "Escuelas Judiciales" o "Institutos de Formación, Capacitación y Especialización", en los que imparten educación judicial mediante cursos, diplomados y estudios de posgrado (especialidades, maestrías y doctorados) sobre diferentes temas relacionados con la administración de justicia, tópicos entre los que destacan aquellos que permitan el eficaz funcionamiento de la reforma al sistema penal mexicano, por lo que, se afirma, los servidores judiciales que se desempeñen como jueces de control contarán con un alto nivel de profesionalización que repercutirá en beneficio de la ciudadanía, y por supuesto en la correcta implementación y desarrollo del nuevo sistema acusatorio. 
de ese centro de investigación, uno de los temas a resolver vinculados al amparo es la cuestión de duplicidad de funciones, porque gran parte de las funciones de garantía que el amparo tiene actualmente, son en la reforma constitucional las que se regulan para el juez de control y por ello propusieron a la Suprema Corte y desde luego, a todos los operadores del sistema revisar la posibilidad de que este ocupe su lugar que hoy tiene el juez de amparo indirecto. ${ }^{12}$

j) Finalmente, si los jueces de control tienen a su cargo garantizar derechos fundamentales del imputado, el ofendido y la víctima, no deben ser considerados, en todos los casos, infractores de esos derechos, sino en todo caso, del control de garantías que les corresponde; por lo que, pienso que no es procedente un juicio de constitucionalidad en contra de sus actos, sino un sistema de recursos, que permita, para algunos casos, abrir una segunda instancia que sirva para calificar o supervisar la función de los jueces de control como garantes de derechos, lo que evita ejercer un control constitucional sobre otro control constitucional. ${ }^{13}$

12 Op. cit., pp. 119 y 120.

13 Esta consideración puede encontrar respaldo en la Tesis P./J. 2/97, del Pleno de la Suprema Corte de Justicia de la Nación, Novena Época, Semanario Judicial de la Federación y su Gaceta, t. V, enero de 1997, p. 5, de rubro y texto siguientes: "AGRAVIOS INOPERANTES. LO SON LOS QUE SOSTIENEN QUE LOS JUZGADORES DE AMPARO VIOLAN GARANTÍAS INDIVIDUALES, SOLAMENTE EN ESE ASPECTO. Históricamente las garantías individuales se han reputado como aquellos elementos jurídicos que se traducen en medios de salvaguarda de las prerrogativas fundamentales que el ser humano debe tener para el cabal desenvolvimiento de su personalidad frente al poder público. Son derechos públicos subjetivos consignados en favor de todo habitante de la República que dan a sus titulares la potestad de exigirlos jurídicamente a través de la verdadera garantía de los derechos públicos fundamentales del hombre que la Constitución Política de los Estados Unidos Mexicanos consigna, esto es, la acción constitucional de amparo. Los Jueces de Distrito, al conocer de los distintos juicios de amparo de su competencia, y no de procesos federales, ejercen la función de control constitucional y, en ese caso, dictan determinaciones de cumplimiento obligatorio y obran para hacer cumplir esas determinaciones, según su propio criterio y bajo su propia responsabilidad, por la investidura que les da la ley por lo que, a juicio de las partes, pueden infringir derechos subjetivos públicos de los gobernados. Ahora bien, aun y cuando en contra de sus decisiones procede el recurso de revisión, éste no es un medio de control constitucional autónomo, a través del cual pueda analizarse la violación a garantías individuales, sino que es un procedimiento de segunda instancia que tiende a asegurar un óptimo ejercicio de la función judicial, a través del cual, el tribunal de alzada, con amplias facultades, incluso de sustitución, vuelve a analizar los motivos y fundamentos que el Juez de Distrito tomó en cuenta para emitir su fallo, limitándose a los agravios expuestos. Luego, a través del recurso de revisión, téc- 
El diseño que, en su caso, queda pendiente, es el relativo a la forma en que debe revisarse la función garantista de los jueces de control y, la articulación que debe mediar entre sus atribuciones y el juicio de amparo.

\section{ARTICULACIÓN ENTRE LA FUNCIÓN DE LOS JUECES DE CONTROL Y EL JUICIO DE AMPARO}

Una de las asignaturas pendientes para el legislador ordinario y, subsidiariamente, para el Poder Judicial de la Federación — por medio de su jurisprudencia - es la articulación entre la función garantista de los jueces de control y el juicio de amparo indirecto.

El diseño a elaborar debe partir del papel que en cada caso desplieguen los jueces de control; es decir, como juez de preparación del juicio oral o como juez de garantía, para así poder delimitar adecuadamente los casos en que, excepcionalmente podrá hacerse valer el juicio de amparo, sin que ello se traduzca en un laberinto para los justiciables.

\section{El papel de preparación del juicio oral y el amparo bi-instancial}

Si se trata del papel del juez de preparación del juicio oral, la procedencia el juicio de amparo bi-instancial podría seguir marchando de la misma forma en que actualmente son impugnables ante los jueces de distrito o el superior jerárquico, las órdenes de aprehensión o los autos de formal prisión (conforme al nuevo sistema: auto de vinculación a proceso).

Es así, porque en estas dos hipótesis los jueces de control ejercerán una función materialmente jurisdiccional, asimilable a la de un juez de proceso criminal, por lo que sus resoluciones pueden ser impugnadas por medio del juicio de amparo como se hace hoy en día, pero mediante un sistema que imprima celeridad al procedimiento de amparo para no detener más de lo necesario el curso del juicio oral.

nicamente, no deben analizarse los agravios consistentes en que el Juez de Distrito violó garantías individuales al conocer de un juicio de amparo, por la naturaleza del medio de defensa y por la función de control constitucional que el a quo desempeña ya que, si así se hiciera, se trataría extralógicamente al Juez del conocimiento como otra autoridad responsable y se desnaturalizaría la única vía establecida para elevar las reclamaciones de inconstitucionalidad de actos, que es el juicio de amparo; es decir, se ejercería un control constitucional sobre otro control constitucional". 


\section{La función de garantía y el juicio de amparo indirecto}

El diseño, sin embargo, no es tan sencillo cuando se trata de delimitar los casos en que puede ser procedente el amparo indirecto en contra de actos o decisiones de los jueces de control, en su actuar como jueces de garantías; en la medida de que parece un contrasentido que puedan violar derechos iusfundamentales, cuando recae en ellos la tutela jurisdiccional de los mismos.

Sin embargo, en nuestra opinión sí puede haber lugar para que puedan ser considerados como autoridad responsable para efectos de ese mecanismo de control ${ }^{14}$ si al resolver sobre medidas cautelares, providencias precautorias y técnicas de investigación, lesionan directamente derechos fundamentales. Esto es así, porque los derechos fundamentales constituyen un orden objetivo de valores que necesariamente debe ser observado por los propios jueces de control o garantías, y de no hacerlo pueden dar lugar a una afectación iusfundamental.

Para fundamentar esta posición señalaré algunos ejemplos:

1. Al legalizar una detención por delito flagrante, 15 el juez de control puede incidir en la violación de la garantía de la libertad del imputado, si legaliza el arresto, a pesar de que no se surtan los supuestos de la flagrancia.

En esta hipótesis, aunque la infracción al derecho fundamental surge a partir de que se materializa la ilegal detención (pensemos que haya sido realizado por la policía); la infracción al derecho fundamental es atribuible, por extensión, al juez de garantía por su ratificación.

2. En el caso de la prisión preventiva, si el Ministerio Público quiere solicitar la aplicación de esta medida cautelar, y pide una audiencia con ese fin, debe mostrar al juez de control, en presencia de la defensa, por lo menos lo siguiente:

14 Ley de Amparo vigente. "Artículo 11. Es autoridad responsable la que dicta, promulga, publica, ordena, ejecuta o trata de ejecutar la ley o el acto reclamado".

15 Artículo 16, párrafo séptimo constitucional: "Nadie puede ser molestado en su persona, familia, domicilio, papeles o posesiones, sino en virtud de mandamiento escrito de la autoridad competente, que funde y motive la causa legal del procedimiento.

(...)

En casos de urgencia o flagrancia, el juez que reciba la consignación del detenido deberá inmediatamente ratificar la detención o decretar la libertad con las reservas de ley". 
a) que ha sucedido un hecho que constituye un delito;

b) el imputado es, con probabilidad el autor de ese hecho o tiene al menos algún grado de participación;

c) hay peligro de fuga; obstaculización de la investigación, y

d) la prisión preventiva es la única medida que puede impedir que ese riesgo se actualice y se frustre el proceso penal.

En este aspecto, si el juez de control autoriza esta medida cautelar, pese a la no satisfacción de alguno o algunos de estos requisitos mínimos; su determinación puede ser objeto de recurso ordinario - cuando lo haya-o del propio juicio de garantías, sin necesidad de agotar algún recurso porque incide en la libertad personal; porque nuevamente aquí, el juez de control al obsequiar la prisión preventiva participa en la lesión al derecho fundamental.

3. Intervención de comunicaciones privadas. El artículo 16 constitucional, párrafo décimo tercero reformado, dispone lo siguiente:

Exclusivamente la autoridad judicial federal, a petición de la autoridad federal que faculte la ley o del titular del Ministerio Público de la entidad federativa correspondiente, podrá autorizar la intervención de cualquier comunicación privada. Para ello, la autoridad competente deberá fundar y motivar las causas legales de la solicitud, expresando además, el tipo de intervención, los sujetos de la misma y su duración...

Por su parte, el artículo 278 ter del Código Federal de Procedimientos Penales (Diario Oficial de la Federación del 23 de enero de 2009) establece que en la autorización el juez federal determinará las características de la intervención, sus modalidades y límites; que cuando sea necesario ampliar a otros sujetos o lugares la intervención se deberá presentar ante el propio juez una nueva solicitud y que el juez autorizante podrá, verificar que las intervenciones sean realizadas en los términos autorizados y, en caso de incumplimiento, decretar su revocación parcial o total.

Estas disposiciones jurídicas denotan que el juez de control no debe desatenderse de la técnica de investigación autorizada, sino que deberá estar atento a los efectos secundarios y posibles de dicha medida, por lo que la evaluación del juez de control no se agota en la inmediatez de la medida.

Bajo ese panorama, si el juez de control federal, a pesar de tener conocimiento de que se han incumplido las condiciones o términos bajo las cuales autorizó la intervención de una comunicación privada debe proceder de 
inmediato a decretar, si así procede, su modificación, o revocación parcial o total; en la inteligencia que de no hacerlo, le es imputable la infracción del derecho fundamental garantizado por el artículo 16 constitucional.

Como es de advertirse, lo que caracteriza a estos casos es que los jueces de control están legalmente facultados para intervenir en la creación, modificación o extinción del acto de injerencia, lo que potencialmente los coloca en infractores del derecho iusfundamental en juego.

Es así, porque como muestra la gráfica siguiente, los jueces de control ejercerán, en ocasiones un control preventivo y complementario al juicio de garantías que debe limitar o eliminar la procedencia del juicio de amparo.

\begin{tabular}{|c|c|c|}
\hline Ámbito de aplicación & Tipo de control & $\begin{array}{l}\text { Procedencia del juicio } \\
\text { de amparo }\end{array}$ \\
\hline $\begin{array}{l}\text { a) Control ex ante y } \\
\text { ex post, sobre medidas } \\
\text { cautelares, providencias } \\
\text { precautorias y técnicas } \\
\text { de investigación de la } \\
\text { autoridad que requieran } \\
\text { control (artículo 16, } \\
\text { párrafo décimo cuarto } \\
\text { constitucional). } \\
\text { b) Control posterior sobre } \\
\text { detenciones realizadas } \\
\text { por el Ministerio Público } \\
\text { (artículo 16, párrafo } \\
\text { séptimo constitucional). } \\
\text { c) Control sobre } \\
\text { cualquier medida } \\
\text { adicional que implique } \\
\text { afectación de derechos } \\
\text { fundamentales en la fase } \\
\text { de investigación (artículo } \\
\text { 16, párrafo décimo cuarto } \\
\text { constitucional). }\end{array}$ & $\begin{array}{l}\text { Preventivo } \\
\text { Intenta limitar o eliminar } \\
\text { la procedencia del juicio } \\
\text { de amparo contra actos } \\
\text { o diligencias surgidos } \\
\text { en la investigación del } \\
\text { delito. }\end{array}$ & $\begin{array}{l}\text { En casos excepcionales } \\
\text { en que subsista alguna } \\
\text { violación a derechos } \\
\text { fundamentales no } \\
\text { remediada por el juez } \\
\text { de control o su superior } \\
\text { jerárquico. }\end{array}$ \\
\hline
\end{tabular}




\begin{tabular}{|c|c|c|}
\hline Ámbito de aplicación & Tipo de control & $\begin{array}{l}\text { Procedencia del juicio } \\
\text { de amparo }\end{array}$ \\
\hline $\begin{array}{l}\text { Control sobre omisiones } \\
\text { del Ministerio Público en la } \\
\text { investigación de los delitos; } \\
\text { resoluciones de reserva; } \\
\text { no ejercicio de la acción } \\
\text { penal; desis-timiento de la } \\
\text { acción penal; suspensión } \\
\text { del procedimiento cuando } \\
\text { no esté satisfecha la } \\
\text { reparación del daño, y } \\
\text { aplicación del criterio de } \\
\text { oportunidad (Artículo 20, } \\
\text { apartado C, fracción VII, } \\
\text { constitucional). }\end{array}$ & $\begin{array}{l}\text { Sustitutivo } \\
\text { El juez de control } \\
\text { remplaza las } \\
\text { competencias de los } \\
\text { jueces de amparo en el } \\
\text { conocimiento de estos } \\
\text { asuntos. }\end{array}$ & $\begin{array}{l}\text { En estos supuestos, las } \\
\text { resoluciones de los jueces } \\
\text { de control, deben ser } \\
\text { impugnadas por medio } \\
\text { de los recursos que prevé } \\
\text { la Ley de Amparo, y ser } \\
\text { del conocimiento, en su } \\
\text { caso, de los Tribunales } \\
\text { Colegiados de Circuito, } \\
\text { como se hace actualmente } \\
\text { respecto de las sentencias de } \\
\text { los jueces de distrito. }\end{array}$ \\
\hline
\end{tabular}

Como podemos advertir de estos cuadros, los jueces de control van a ejercer un control ex ante y ex post, sobre medidas cautelares, providencias precautorias y técnicas de investigación de la autoridad que requieran control (artículo 16, párrafo décimo cuarto constitucional); un control posterior sobre detenciones realizadas por el Ministerio Público (artículo 16, párrafo séptimo constitucional), y un control sobre cualquier medida adicional que implique afectación de derechos fundamentales en la fase de investigación (artículo 16, párrafo décimo cuarto constitucional).

Aquí, el tipo de control asignado a los jueces de control, es preventivo, en la medida de que intenta limitar o eliminar la procedencia del juicio de amparo, dado que, en su función de garantía los jueces de control no sólo deben concretarse a autorizar la medida cautelar, providencia precautoria o técnica de investigación, sino que valiéndose de los principios jurídicos de proporcionalidad y razonabilidad jurídica, deben vigilar que el acto de injerencia o molestia, infrinjan o limiten, sólo en la medida de lo necesario el derecho fundamental en juego.

Los jueces de control deben asumirse, como verdaderos garantes de derechos fundamentales, para ello deberán estar próximos, visibles, a los gobernados. Es preciso destacar que su función de control no termina al momento de autorizar cualesquiera de esos actos, sino que su control o 
verificación sobre el Ministerio Público debe ser permanente o continuo, a efecto de que, en vista de cualquier reclamación, se pronuncien nuevamente sobre el mantenimiento o cancelación del acto inicialmente autorizado.

Por ser un control inmediato al Ministerio Público, es previsible que los reclamos por infracción a derechos fundamentales sean reparados por el juez de control y sólo de manera subsidiaria operará el amparo, cuando la violación al derecho fundamental no haya quedado reparada, ante la potestad de los jueces de control y excepcionalmente, cuando los propios acuerdos de los jueces de control lesionen algún derecho fundamental.

En cambio, es de tipo complementario el control que tendrán que ejercer sobre los reclamos por omisiones del Ministerio Público en la investigación de los delitos; resoluciones de reserva; no ejercicio de la acción penal; desistimiento de la acción penal; suspensión del procedimiento cuando no esté satisfecha la reparación del daño. ${ }^{16}$

El Código de Procedimientos Penales para el Estado de México (siguiendo la directriz establecida en la exposición de motivos de la reforma constitucional) en el artículo 150 fracción XIV, contempla el derecho de la víctima y el ofendido para impugnar ante el juez de control las omisiones del Ministerio Público en la investigación de los delitos así como las resoluciones de reserva, no ejercicio, y desistimiento de la acción penal o la suspensión condicional del proceso a prueba cuando no esté satisfecha la reparación del daño. Igualmente el Código de Procedimientos Penales para el Estado de Chihuahua (última reforma del 19 de febrero de 2011), en su artículo 227, dispuso que las decisiones del Ministerio Público sobre el archivo temporal, abstenerse de investigar y no ejercicio de la pretensión punitiva u omisiones de la investigación, podrán ser impugnados por la víctima u ofendido ante el juez de garantía.

En estas hipótesis, los jueces de control no participan en la creación del acto que puede resultar violatorio de derechos fundamentales, porque las determinaciones del Ministerio Público sobre ejercicio o inejercicio de la acción penal, derivan de sus atribuciones constitucionales como titular de la acción penal. ${ }^{17}$

16 En los dictámenes de las cámaras de diputados y senadores, relativos a la reforma de junio de 2008, se dejó establecido que otra atribución del juez de control sería conocer las impugnaciones de las resoluciones de reserva, no ejercicio de la acción penal, el desistimiento y la suspensión de la acción penal, para controlar su legalidad.

17 Constitución Política de los Estados Unidos Mexicanos: "Artículo 21. La investigación de los delitos corresponde al Ministerio Público y a las policías, las cua- 
En conclusión, un diseño viable, es que las resoluciones de los jueces de control en su función de garantías, puedan ser impugnadas, mediante el recurso de revisión previsto en la Ley de Amparo, pues de ese modo se adoptaría el mismo sistema recursal que opera actualmente para la impugnación de las sentencias de los jueces de amparo, lo que permitiría cierta uniformidad sobre los criterios que deben imperar en materias tan importantes como son las relativas al ejercicio o inejercicio de la acción penal, aplicación de criterios de oportunidad, entre otras.

También sería viable pensar, en una jurisdicción concurrente, asignable a los tribunales de alzada, para que si la parte interesada, así lo estima conveniente y oportuno a sus intereses, acuda a dichos órganos jurisdiccionales a hacer valer ese recurso, con la condición de que sería terminal, es decir, sin posibilidad de ulterior impugnación. Lo que se trata es facilitar a los gobernados el acceso a la jurisdicción, pero también debe respetarse su derecho de acudir a las instancias federales si encuentran alguna dificultad en la justicia local. ${ }^{18}$

\section{CONCLUSIONES}

Primera. El 18 de junio de 2008 se publicó en el Diario Oficial de la Federación el decreto de reformas constitucionales que establece un proceso penal y acusatorio en México. El Constituyente Permanente introdujo en la reforma constitucional penal, la figura de los jueces de control, como nuevos integrantes de los poderes judiciales federal y local.

El poder reformador determinó que esta clase de jueces emitirán resolución, en forma inmediata sobre medidas cautelares, providencias precautorias

les actuarán bajo la conducción y mando de aquél en el ejercicio de esta función. El ejercicio de la acción penal ante los tribunales corresponde al Ministerio Público. La ley determinará los casos en que los particulares podrán ejercer la acción penal ante la autoridad judicial"'.

18 En su libro El sistema federal mexicano, el doctor José María Serna de la Garza, se ocupa de examinar el juicio de amparo directo, que actualmente es un recurso imprescindible de los ciudadanos de las entidades federativas para contrarrestar la influencia que personajes poderosos ejercen sobre la justicia estatal. En ese sentido, el autor destaca que el amparo directo ha sido la gran "válvula de escape" que los litigantes locales han tenido para darle la vuelta a una justicia del fuero común sometida a poderosas influencias locales. Serna de la Garza, José María, El sistema federal mexicano. Un análisis jurídico, México, Porrúa-UNAM, 2009, p. 350. 
y técnicas de investigación "garantizando los derechos de los indiciados y de las víctimas u ofendidos". Mas no dejó en claro, el alcance de sus atribuciones como garantes de esos derechos, ni el tipo de sistema recursal aplicable a sus resoluciones.

Segunda. La importancia de conocer la naturaleza y funciones de los jueces de control es de interés no sólo porque se trata de una figura novedosa, sino porque la reforma constitucional les asigna el papel de garantes de derechos fundamentales de los indiciados, las víctimas u ofendidos y por ende, es necesario dilucidar el tipo de control judicial que les corresponde, como garantes de derechos fundamentales $\mathrm{y}$, especialmente delimitar si su función es meramente instrumental o alcanza alguna proyección en el sistema de control de constitucionalidad en México.

Tercera. Conforme al diseño de la reforma constitucional de junio de 2008, los jueces de control deben ser considerados como depositarios de un nuevo mecanismo de regularidad de la norma suprema, porque son jueces creados ex profeso por el Constituyente Permanente para garantizar derechos fundamentales, mediante un control que pretende actuar y hacer valer las situaciones jurídicas subjetivas del ciudadano, previamente constitucionalizadas, que redundan también en tutela y garantía de la norma constitucional.

Cuarta. Si los jueces de control tienen a su cargo garantizar derechos fundamentales del imputado, el ofendido y la víctima, no pueden ser considerados, en todos los casos, como infractores de esos derechos, sino en todo caso, del control de garantías que les corresponde.

Quinta. El tipo de control que corresponde a estos jueces, es en ocasiones de carácter preventivo, cuando se ejerce sobre medidas cautelares, providencias precautorias y técnicas de investigación; que intenta limitar o eliminar la procedencia del juicio de amparo.

Pero también, puede identificarse como un control sustitutivo, en relación al juicio de garantías, el que ejercerán al verificar la legalidad sobre las omisiones del Ministerio Público en la investigación de los delitos; resoluciones de reserva; no ejercicio de la acción penal; desistimiento de la acción penal y suspensión del procedimiento, cuando no esté satisfecha la reparación del daño y al controlar la aplicación del criterio de oportunidad.

En este último supuesto, la resoluciones de los jueces de control, deben ser impugnadas por medio de los recursos que prevé la Ley de Amparo, y ser del conocimiento de los tribunales colegiados de circuito, como se hace actualmente respecto de las sentencias de los jueces de distrito. 


\section{BIBLIOGRAFÍA}

Brage CAMAZANO, Joaquín, La jurisdicción constitucional de la libertad, México, Porrúa, 2005.

CAPPELletTI, Mauro, La giurisdizione costituzionale delle libertà, Milán, Giuffrè, 1955. Hay traducción al castellano de Héctor Fix-Zamudio, $L a$ jurisdicción constitucional de la libertad, México, UNAM, 1961.

FIX-ZAMUDIO, Héctor, Justicia constitucional ombudsman y derechos humanos, México, Comisión Nacional de Derechos Humanos, 1997.

GARCÍA RAMíREZ, Sergio, La reforma constitucional en materia penal (Jornadas de Justicia Penal), México, Instituto Nacional de Ciencias Penales, 2009.

GonZÁlez OropezA, Manuel, Constitución y derechos humanos, orígenes del control jurisdiccional, México, Porrúa, 2009.

SERNA DE LA GARZA, José María, El sistema federal mexicano. Un análisis jurídico, México, Porrúa-UNAM, 2009.

SUPREMA CORTE DE JUSTICIA DE LA NACIÓN, El sistema penal acusatorio en México: estudio sobre su implementación en el Poder Judicial de la Federación, México, 2008.

ZALDÍVAR LELO DE LARREA, Arturo, "El juicio de amparo y la defensa de la Constitución”, en Cossío, José Ramón y PÉREZ DE ACHA, Luis M. (comps.), La defensa de la Constitución, México, Fontamara, 1997.

Fuentes electrónicas

CASCAJO CASTRO, José Luis, La jurisdicción constitucional de la libertad, en http://www.cepc.es/rap/Publicaciones/Revistas/2/REP_199_153. $p d f$.

\section{Hemerografía}

"CONTROVERSIA CONSTITUCIONAL. LA FACULTAD OTORGADA A LA SALA Constitucional del Tribunal Superior de Justicia del Estado DE VERACRUZ-LLAVE PARA CONOCER Y RESOLVER EL JUICIO DE PROTECCIÓN DE DERECHOS HUMANOS, PREVISTO EN LA CONSTITUCIÓN POLÍTICA DE ESA ENTIDAD FEDERATIVA, NO INVADE LA ESFERA DE ATRIBUCIONES DE LOS TRIBUNALES DE LA FEDERACIÓN, PUES AQUÉL SE LIMITA 
A SALVAGUARDAR, EXCLUSIVAMENTE, LOS DERECHOS HUMANOS QUE ESTABLECE EL PROPIO ORDENAMIENTO LOCAL". Semanario Judicial de la Federación y su Gaceta, Novena Época, Pleno, t. XV, junio de 2002 , p. 406.

“CONTROL JUDICIAL DE LA CONSTITUCIÓN. ES ATRIBUCIÓN EXCLUSIVA DEL Poder Judicial DE LA FEDERACiÓN", Semanario Judicial de la Federación y su Gaceta, registro 193558, Novena Época, t. X, agosto de 1999, P./J. 73/99.

"AGRAVIOS INOPERANTES. LO SON LOS QUE SOSTIENEN QUE LOS JUZGADORES DE AMPARO VIOLAN GARANTÍAS INDIVIDUALES, SOLAMENTE EN ESE ASPECTO", Semanario Judicial de la Federación y su Gaceta, registro 199,492, Pleno, t. V, Novena Época, enero de 1997.

\section{Legislación}

Constitución Política de los Estados Unidos Mexicanos

Ley de Amparo

Iniciativa con proyecto de decreto por el que se expide la Ley de Amparo 